\title{
Plant Growth Promoting and Biocontrol Potential of Pseudomonas sp. Strains on Sorghum (Sorghum bicolor) Plant
}

\section{Mounika Nagabhairava, Ali Shaik Zulfikar, Sandhya Vardharajula and Sai Shiva Krishna Prasad Vurukonda*}

Department of Microbiology, Agribiotech Foundation, PJTSAU Campus, Hyderabad, Telangana State, India

*Corresponding Author: Sai Shiva Krishna Prasad Vurukonda, Department of Microbiology, Agribiotech Foundation, PJTSAU Campus, Hyderabad, Telangana State, India.
Received: March 22, 2021

Published: April 19, 2021

(C) All rights are reserved by Sai Shiva

Krishna Prasad Vurukonda., et al.

\begin{abstract}
Extensive studies on the use of biocontrol agents (BCA's) to control diseases caused by plant pathogenic microorganism, to reduce the over usage of chemical inputs and to minimize broad use of fungicides, which leads to resistance in plant pathogens. In sustainable agriculture, plant growth promoting (PGP), and BCA's have emerged as eco-friendly alternatives to most of the chemical pesticides. In the present study, six Pseudomonas spp. strains were screened for various PGP traits viz., Indole-3-Acetic Acid (IAA), Phosphate solubilization, siderophore activity, hydrogen cyanide (HCN) production and furthermore the strains were characterized for in vitro antifungal activity against various plant pathogenic fungi, drought, and temperature tolerance. The strains $\mathrm{P} 21-\mathrm{ABF}$ and P22-DSK has shown effective PGP traits and antagonistic activity against Rhizoctonia solani and Fusarium oxysporum. The most prospective strains P21-ABF and P22-DSK were selected to perform in planta biocontrol studies on sorghum seeds. The most prospective strain P21-ABF upon molecular characterization was identified as Pseudomonas aeruginosa.
\end{abstract}

Keywords: Plant Growth Promotion; Biocontrol; Agriculture and Plant Pathogens

\section{Introduction}

Plant growth promoting bacteria (PGPB) have an important role in agriculture especially eco-friendly sustainable agriculture practices. These bacteria not only minimize the usage of chemicals, but they also help in accumulation plant minerals. PGPB perhaps, develops a useful (beneficial) interactions with plants especially by colonizing roots and they enhance plant strength and also increase soil [1]. These beneficial effects can be direct or indirect results on plants. Growth promotion as direct mechanism by PGPR includes production of secondary metabolites that enhances plant growth such as growth hormones like Auxins [2], cytokinins, gibberellins [3]. Indirect mechanism occurs via the inhibition of pathogens by the production volatile compounds such as hydrogen cyanide and Iron (Fe) chelating siderophores [4]. PGPR also antagonize plant pathogens and/or induce systemic resistance in the plant to various fungal and bacterial diseases [5,6]. Because plants lack effector-triggered immunity to many soilborne pathogens, they rely on PGPR for defence against pathogen attack [5]. Rhizosphere has wide microbiome populations in the form of epiphytes (on surface) and endophytes (inside plant tissues) [7]. For the last 30 years usage of microbial inoculants as commercial formulations has increased extensively which is an important alternative to minimize application of synthetic nutrients which helps towards healthy environment [2]. In bacteria genera Pseudomonas sp. is most studied because of having unique characteristics of processing multiple PGP traits. Their PGP activities include production of HCN, siderophores, pectinolytic enzymes, antimicrobial compounds, phosphate solubilizing enzymes $[8,9]$. Therefore, in the current research 
we hypothesized that rhizobacteria isolated from arid rhizosphere soils may induce and support plant growth and biocontrol activity under biotic or abiotic stress condition. To report this hypothesis, we isolated six Pseudomonas sp. strains and were investigated to produce HCN, siderophores, phosphate solubilization and biocontrol activity.

\section{Materials and Methods}

Screening for PGP traits indole-3-acetic acid

Luria Bertani (LB) broth with added $5 \mathrm{mmol}$ tryptophan media was inoculated with $1 \%$ overnight culture $(0.1 \mathrm{OD}$ at $600 \mathrm{~nm})$ grown in LB broth and incubated at $28{ }^{\circ} \mathrm{C}$ for $48-72 \mathrm{~h}$ on incubator shaker. Cell pellet was obtained by centrifugation at 5000rpm for $5 \mathrm{~min}$ and the resulted supernatant was mixed with freshly prepared Salkowsky reagent and incubated for $1 \mathrm{~h}$ at room temperature under dark conditions which develops pink pigmentation and absorbance was measured at $530 \mathrm{~nm}$ spectrophotometrically [10]. By Bradford method the auxin (IAA) was estimated in terms of protein using the cell pellet and concentration was expressed as $\mathrm{mg} /$ mg cell protein.

\section{Siderophore production}

To determine siderophore production $10 \mu$ of bacterial culture was spot inoculated on Chrome Azurol S (CAS) agar plates and incubated at $28^{\circ} \mathrm{C}$ for five days. Development of orange halo around the colony was considered as positive for siderophore production [11].

\section{Production of HCN}

The production of HCN was detected by streaking of test bacterial culture on King's B agar plates prepared by adding $0.4 \%$ glycine and plates were incubated with Whatmann No. 1 filter paper flooded with picric acid solution (0.5\% picric acid in $2 \%$ sodium carbonate) located in the upper lid of petri dish. To prevent the escape of volatile compounds plates were sealed with parafilm. After 24-48 h, color change from yellow to orange of filter paper was observed [12].

\section{Phosphate solubilization activity}

For qualitative estimation of phosphate solubilization activity, $10 \mu \mathrm{l}$ test bacterial culture was spot inoculated on Pikovskya's agar plate and incubated for $3-5$ days at $30^{\circ} \mathrm{C}$. Halozone around the colony indicates the phosphate solubilization positive and is measure using the below formula [13]:

Phosphate solubilization index (PSI) $=$ A/BX100 (A-Colony + Halozone diameter and B-Colony diameter).
Screening for drought and temperature stress

Trypticase soya broth (TSB) with different water potentials $(-0.05,-0.15,-0.30,-0.49,-0.73$ and $-1.03 \mathrm{MPa})$ was prepared by adding appropriate concentrations of polyethylene glycol (PEG6000) [14] and was inoculated with 1\% of overnight raised cultures of the bacterial isolates in TSB and incubated at $28^{\circ} \mathrm{C}$ for $24 \mathrm{~h}$ in shaking incubator at $120 \mathrm{rpm}$. Three replicates of each isolate and each concentration were prepared. Bacterial growth was measured spectrophotometrically at $600 \mathrm{~nm}$. Same method was followed to screen the test bacteria for temperature stress tolerance ranged $28^{\circ} \mathrm{C}$ to $65^{\circ} \mathrm{C}$ [15].

\section{Antifungal activity}

Determination of the antifungal activity of test bacteria was performed according to the cross streak method by Fernando [16]. In short, the PDA plate was inoculated with $24 \mathrm{~h}$ old pure test bacteria as single streak at both the ends of petri plate and incubated at room temperature for $48 \mathrm{~h}$. After incubation, the test plates and control plates were spot inoculated with $5 \mathrm{~mm}$ fungal pathogen disc in the centre and without disturbing plates were incubated at $28 \pm 1^{\circ} \mathrm{C}$ for another $5-7$ days depending on the fungi tested. By comparing the growth of fungi in both test and control plates were measured and statistical data was prepared to observe the inhibition of fungi by test bacteria [17].

\section{In planta plant growth and biocontrol activity on Sorghum}

Agricultural field soil collected at Agriculture research farm, PJTSAU campus, Hyderabad, India, was used to study the efficacy of two drought tolerant PGP Pseudomonas sp. strains $\left(\mathrm{P}_{21}\right.$-DSk and $\mathrm{P}_{22}-\mathrm{DSK}$ ) in alleviating plant growth and biocontrol effects in host plant sorghum (Sorghum bicolor) as described earlier [15]. Sorghum seeds were surface sterilized with $0.1 \% \mathrm{HgCl}_{2}$ followed by $70 \%$ ethanol and washed multiples times with sterile distilled water. After drying seeds were inoculated with test bacteria either with liquid form or carrier based solid form having $\sim 10^{8} \mathrm{cfu} / \mathrm{mL}$ or/g and dried under cool place and planted into plastic pots filled with sterile soil. Different treatments of inoculated and uninoculated samples were replicated three times, maintaining three plants per pot. The pots were kept under greenhouse conditions and daily sprinkling with sterile distilled water. After 30 days of germination the plant lets were assed for root $\&$ shoot length and dry biomass.

\section{Molecular characterization}

The selected bacterial isolates were screen for microscopic, morphological and biochemical characterization according to Bergey's manual of determinative bacteriology. For molecular analysis, genomic DNA was extracted [18], and the 16S rRNA gene 
was amplified by polymerase chain reaction (PCR) using universal forward (5'-AGAGTTTGATCCTGGCTCAG-3') and reverse

(5'-AAGGAGGTGATCCAGCCGCA-3') primers using standard conditions (initial denaturation $94^{\circ} \mathrm{C}$ for $5 \mathrm{~min} ; 30$ cycles of denaturation at $94{ }^{\circ} \mathrm{C}$ for $30 \mathrm{~s}$, annealing at $50{ }^{\circ} \mathrm{C}$ for 40 s, extension at $72{ }^{\circ} \mathrm{C}$ for 90s; final extension at $72{ }^{\circ} \mathrm{C}$ for $7 \mathrm{~min}$. The PCR product ( $\left.\sim 1500 \mathrm{bp}\right)$ was purified and sequenced (Xcelris Lab, Ahmadabad, India). The sequence (16S rRNA gene) obtained was compared with the existing data base of 16S rRNA gene sequence present at NCBI GenBank.

\section{Results}

PGP and antifungal activity

Based on cultural and morphological characteristics a total of six strains isolated from different rhizospheric soil samples were selected tentatively as Pseudomonas spp. based on the initial morphology and fluorescence nature under UV light on King's B agar media. Isolates screened for drought and temperature tolerance in
TSB at varying water potential and different temperature. Out of five potential Pseudomonas spp. strains, only two could be able to grow at minimum water potential of $-1.03 \mathrm{MPa}$ and at higher temperature of $45^{\circ} \mathrm{C}$ (Figure 2 and 3), and all strains were screened in vitro for PGP traits. All strains were able to produce IAA and strain P22-DSK showed highest production ( $50.4 \pm 1.1 \mu \mathrm{g} / \mathrm{mg})$ and strain $\mathrm{P} 21-\mathrm{ABF}(37.6 \pm 1.2 \mu \mathrm{g} / \mathrm{mg})$ is next among other strains (Table 1). P-solubilization activity was confined only to $70 \%$ isolates and the highest solubilization index was confined to strain P21-ABF (189 \pm 2.2 ) and strain P22-DSK showed second highest (158.30 \pm 1.9 ) among other strains, but all the stains produced ammonia (99\%) and interestingly siderophores and HCN were observed only in one strain P21-ABF (Table 1 and figure 1). Interestingly only two strains P21-ABF and P22-DSK were effectively inhibited the pathogenic fungal growth Rhizoctonia solani and Fusarium oxysporum strains. Strain P21-ABF showed 84\% and 74\% inhibition and strain P22DSK showed $79 \%$ and $68 \%$ growth inhibition, respectively.

\begin{tabular}{|l|c|c|c|c|c|c|}
\hline \multirow{2}{*}{ Strain } & IAA $(\boldsymbol{\mu g} / \mathbf{m g}$ & $\begin{array}{c}\text { Phosphate } \\
\text { protein) }\end{array}$ & $\begin{array}{c}\text { Solubilization } \\
\text { Index }\end{array}$ & Production & $\begin{array}{c}\text { HCN } \\
\text { Activity }\end{array}$ & \multicolumn{2}{|c|}{$\begin{array}{c}\text { In vitro \% of radial growth inhibition } \\
\text { of pathogenic fungi }\end{array}$} \\
\cline { 5 - 7 } & & $189.33 \pm 2.2$ & + & + & $84.48 \pm 4.20$ & $79.34 \pm 3.90$ \\
\hline P21-ABF & $37.6 \pm 1.2$ & $158.30 \pm 1.9$ & - & - & $70.23 \pm 2.88$ & $68.71 \pm 3.21$ \\
\hline P22-DSK & $50.4 \pm 1.1$ & - & - & - & - \\
\hline P1 & $31.8 \pm 1.0$ & $150.40 \pm 1.8$ & - & - & - & - \\
\hline PF-R5 & $27.6 \pm 0.9$ & - & - & - & - & - \\
\hline PF-SA4 & $19.2 \pm 1.0$ & - & - & - & - & - \\
\hline
\end{tabular}

Table 1: PGP and antifungal activity of test isolates. Numerical values are mean \pm SD $(n=3)$. IAA: Indole Acetic Acid; HCN: Hydrogen Cyanide; +: Positive; -: Negative.

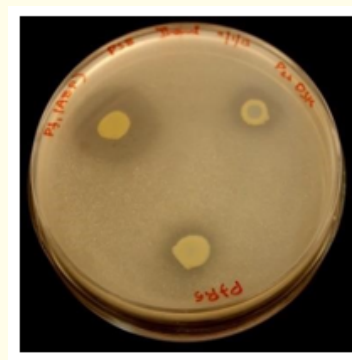

A

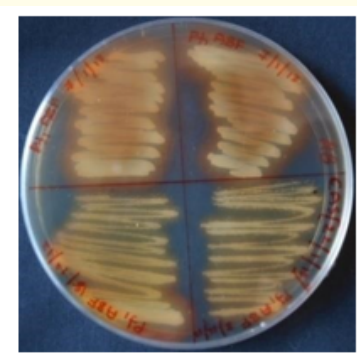

B

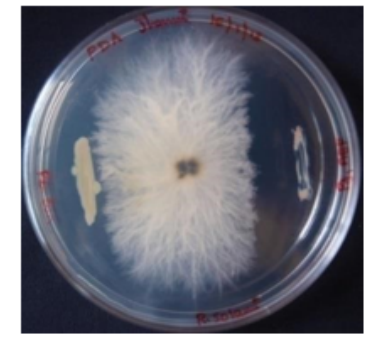

C

Figure 1: Showing in vitro PGP and antifungal activity: A; P-solubilization, B; Siderophore activity, C; Antifungal activity of P21-ABF against Rhizoctonia solani. 


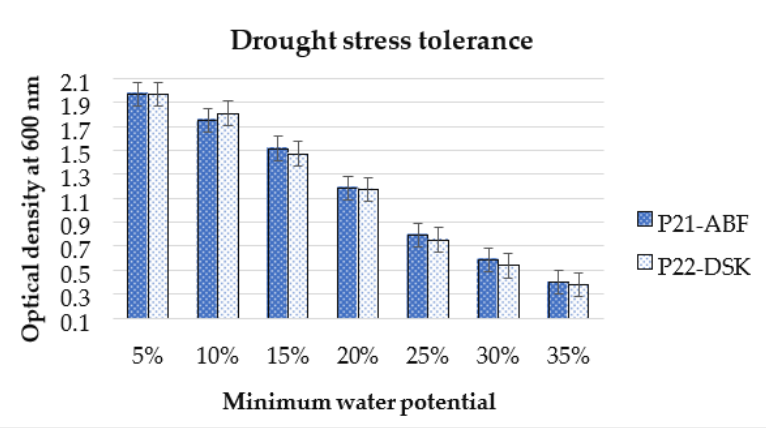

Figure 2: In vitro drought stress tolerance of test isolates, mean \pm $\operatorname{SD}(\mathrm{n}=3)$.

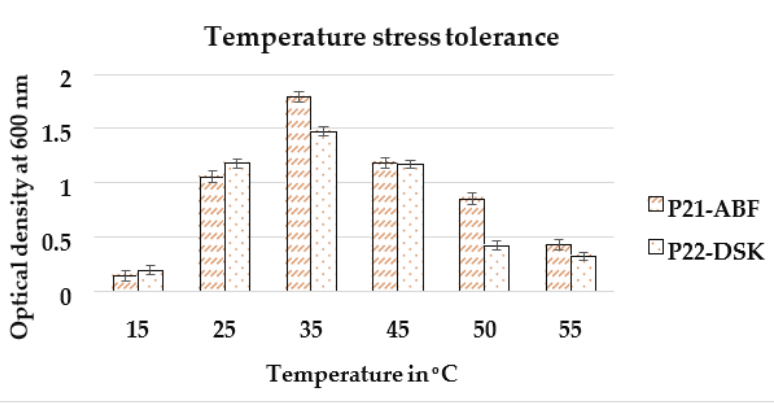

Figure 3: In vitro temperature stress tolerance of test isolates, mean $\pm \operatorname{SD}(\mathrm{n}=3)$.
In planta assay

Plant growth promoting and biocontrol ability of microbial inoculation studies of two Pseudomonas spp. strains P21-ABF and P22-DSK were evaluated in Sorghum as model plant. Different test treatments such as seeds without any treatment as control, seeds treated with antagonistic bacteria, seeds with fungal pathogen and seeds with both antagonist and fungal pathogen. In all treatments, seeds were surface sterilized with $0.5 \% \mathrm{NaOCl}$ (Sodium hypochlorite) and followed by washing with sterile distilled water for several times. After 25 days the physiological parameters like shoot, root lengths and dry mass of the seedlings were evaluated (Table 2). Results highlighted the positive effects of strain P21-ABF as a very effective growth promoter, thus significantly increasing the shoot $(\sim$ $+17 \%)$, root $(\sim+70 \%)$ and dry mass $(\sim+84 \%)$ than control plants.

Molecular characterization of Pseudomonas sp. strain P21$\mathrm{ABF}$

The effective isolate selected based on PGP characters, abiotic $\&$ biotic stress tolerance was characterized based on microscopic, morphological, and biochemical studies. Gram staining method revealed that the isolate P21-ABF was gram -ve, motile, rod-shaped bacteria. On King's B agar medium colonies appeared as creamy, smooth, shiny, circular, convex with greenish pigmentation observed under UV light. From molecular analysis, 16s rRNA gene sequence blast showed $99 \%$ homology with existing gene data and the strain P21-ABF was identified as Pseudomonas aeruginosa.

\begin{tabular}{|c|c|c|c|c|}
\hline Treatment & Inoculum & Shoot length (cm) & Root length (cm) & Dry mass (gm) \\
\hline $\mathrm{T} 1$ & Only seed & 38.5 & 31.5 & 0.125 \\
\hline $\mathrm{T} 2$ & Seed + Rhizoctonia & 18.5 & 21.4 & 0.130 \\
\hline T3 & Seed + Fusarium & 22.4 & 23.9 & 0.121 \\
\hline $\mathrm{T} 4$ & Seed + P21-ABF & 43.6 & 65.2 & 0.345 \\
\hline T5 & Seed + P22-DSK & 41.5 & 61.7 & 0.302 \\
\hline T6 & Seed + Rhizoctonia + P21-ABF & 40.0 & 47.1 & 0.204 \\
\hline $\mathrm{T} 7$ & Seed + Fusarium + P21-ABF & 38.1 & 56.4 & 0.261 \\
\hline T8 & Seed + Rhizoctonia + P22-DSK & 35.1 & 39.3 & 0.279 \\
\hline T9 & Seed + Fusarium + P22-DSK & 37.7 & 45.4 & 0.285 \\
\hline $\mathrm{T} 10$ & Seed + Rhizoctonia + Fusarium + P21-ABF & 45.3 & 53.8 & 0.231 \\
\hline T11 & Seed + Rhizoctonia + Fusarium + P22-DSK & 42.0 & 49.1 & 0.222 \\
\hline
\end{tabular}

Table 2: Physiological parameters of Sorghum plants after treated with different test controls.

Cm: Centimeter; gm: Gram. 


\section{Discussion}

The PGPR can competitively and effectively colonize plant roots and promote plant growth by reducing the population of deleterious bacterial/fungal phytopathogens. Plants were continuously exposed to various stress conditions (biotic and abiotic) and is considered as serious problem to agriculture affecting crop yield. The outline of stress (biotic and abiotic) tolerant microbial bioinoculants in agricultural soils can alleviate various stress conditions in crop plants by lowering stress-induced ethylene production. Stress tolerant bacteria/fungi can survive in these conditions and attach to the seed surface or colonize roots, results in the deamination of ACC, which is the precursor of ethylene, in plant cells through the production of ACC deaminase enzyme. This leads to lowering of the plant ethylene level and facilitates the growth and development of plants [19].

In our results, strains P21-ABF, P22-DSK and P4-DSK showed phosphate solubilization, except P1, PF-R5 and PF-SA4. These phosphate solubilizing microbes (PSM) have an important role in plant growth by making available insoluble phosphorus to soluble phosphates to plants. Therefore, the widespread and commercial application of PSM in plant growth promotion helps to reduce both escalating cost of phosphate fertilizers and to maintain the fertility of soil. Considering abovementioned points, the PSM presented with multiple PGP traits have more prospective to be used to enhance the plant productivity and growth [20]. Among many plant growth promoting rhizobacteria Pseudomonas and Bacillus spp. were extensively studied genera of phosphate solubilization activity [21]. The group of bacteria belongs to Bacillus, Pseudomonas, Acinetobacter spp. were evidenced to be as effective p-solubilizers, as well as phytohormone producers [22]. IAA production by microbes has positive effect on root system elongation and development which helps in the uptake of water and essential nutrients, this may lead to the increased root growth and develop a healthy plant as compared to control. All the six strains showed significant IAA production with the difference in their values. Out of six, two isolates produce higher IAA concentration with the value of 50.4 $\mu \mathrm{g} / \mathrm{mg}$ for P22-DSK, $37.6 \mu \mathrm{g} / \mathrm{mg}$ for P21-ABF compared to previous reports of Rana., et al. [23]; Zhang., et al. [24]. Among the isolates only P21-ABF can be able to produce HCN and siderophore. Hydrogen cyanide production is a control mechanism by bacterial antagonists against broad range of phytopathogens [25]. Beneficial PGPR produce such secondary metabolites which were considered as BCAs against various plant pathogens. Also, HCN have indirect ability to increase the availability of soluble phosphate and iron to plants, resulting in enhanced plant growth [26]. Siderophores of PGP bacteria can promote plant growth through improved direct iron availability to plants under iron deficient conditions or by eliminating the availability of iron to pathogens [27]. Biocontrol ability was considered as important characteristics for the isolates whether they produce PGP traits or not. Amongst all, only two isolates were able to inhibit $F$. oxysporum and $R$. solani were therefore identified as PGPR. Isolates showing biocontrol ability were prospective PGPR because of their indirect effect on plant growth by inhibiting various pathogens [28]. Earlier reports suggest plant root exudates plays an important role in the alteration of rhizobacterial populations and can affect the incidence of antagonistic bacteria [29].

Two out of six isolates P21-ABF and P22-DSk were able to grow at a minimum water potential $(-1.33 \mathrm{MPa})$. Low osmotic levels (-0.30 MPa) and EPS-production by stress tolerant bacteria were probably because of the naturalization in the semiarid habitats. EPS production is possible reason to a response to matric stress [30]. Microbial EPS has exclusive water retention 45and cementing characteristics, which protect bacteria against desiccation and various stress conditions through improved soil fertility and formation of soil aggregates at root level [31,32]. Indeed, an increase in EPS production in A. brasilense Sp245 was regarded as responsible protection under extreme drought situations [33]. The drought tolerance of the two rhizobacteria could be explained by production of EPS. Similarly, these two strains were also able sustain at a maximum temperature of $55^{\circ} \mathrm{C}$ and the optimum growth of these two strains was at $35^{\circ} \mathrm{C}$ where the growth of bacteria was high compared to all the temperature tested. Though there was a significant reduction in the bacterial growth as the temperature increases. Our present results were likely to the study conducted by Ali., et al. [34] he demonstrated increased growth of wheat plants by temperature tolerant $P$. putida strain AKMP-7. Based on preliminary studies on PGP traits like biocontrol and abiotic stress tolerance, bacterial isolates P21-ABF and P22-DSK were further screened for pot studies to evaluate growth promotion of Sorghum (Sorghum bicolor $\mathrm{L}$ ). The initial bacterial count of P21-ABF and P22-DSK per seed was $1 \times 10^{7}$ colony forming units, respectively. We performed different treatments with different combinations of bacteria with and without pathogen. These two bacterial isolates significantly enhanced the growth sorghum plants (Table 2). However, of the 
two isolates, P21-ABF showed significantly higher growth promotion in terms of increase root, shoot and dry biomass weight than P22-DSK in all combinations performed. Previously, many PGPB species viz., Bacillus, Pseudomonas, Acinetobacter, Rahnella were reported for their ability enhance growth promotion studies on various plants [35]. A B. pumilus strain isolated from maize root surface has shown growth promoting effects on maize plants under greenhouse conditions [36]. Similarly, B. subtilis strain able to produce IAA and enhanced plant growth by increasing the number of root hairs [37].

To confirm the identity of the most prospective bacterial isolate P21-ABF, 16S rDNA gene sequencing was carried out since the $16 \mathrm{~S}$ rDNA gene is the most used marker for reasoning the phylogenetic relationship between bacteria due to its universal distribution, highly conserved nature and its rate of evolution [38]. 16S rDNA gene analysis of $1500 \mathrm{bp}$ sequence of P21ABF showed $99 \%$ sequence similarity with $P$. aeruginosa upon blast on NCBI GenBank. The bacterial isolate P21-ABF identification was much likely to the previous studies by [39] and his group isolated plant growth promoting, and antagonistic Bacillus spp. have earlier been reported for their stress tolerance against salinity, temperature and desiccation.

\section{Conclusion}

In PGPR world there were number of examples of effective biocontrol agents, the future challenge is not to prove that biocontrol is possible, but to improve efficacy and robustness of biocontrol activity, most importantly in field level studies. This will be achieved through a better understanding of the antagonism mechanisms, plant-microbe interactions and processes as well as microbial ecology in the soil and rhizosphere. In the present study, the Pseudomonas sp. strain P21-ABF was selected as a prospective strain to be used as a microbial inoculant in a stressful environment as it showed stress tolerance against all tested stress levels, exhibited antagonisms and multiple PGP activities. These types of prospective strains need in the process of sustainable agriculture strategies in various biotic and abiotic stress conditions. Since the strain P21ABF was identified as Pseudomonas aeruginosa which is regarded as the human pathogen and identified some clinical relevant due to which these type of strains cannot be used as microbial inoculants for further field level studies, but the research carried out in the present study will be helpful as a model work to carry out the experiments on other PGP strains activity of P21-ABF against Rhizoctonia solani.

\section{Bibliography}

1. Dastager SG., et al. "Potential plant growth-promoting activity of Serratia nematodiphila NII-0928 on black pepper (Piper nigrum L.)". World Journal of Microbiology and Biotechnology 27 (2011): 259-265.

2. Ali B., et al. "Rhizobacterial potential to alter auxin content and growth of Vigna radiata (L.)". World Journal of Microbiology and Biotechnology 26 (2010): 1379-1384.

3. El-Hadad ME., et al. "In vitro evaluation of some bacterial isolates as biofertilizers and biocontrol agents against the second stage juveniles of Meloidogyne incognita". World Journal of Microbiology and Biotechnology 26 (2010): 2249-2256.

4. Idris HA., et al. "Suppression of Pythium ultimum root rot of sorghum by rhizobacterial isolates from Ethiopia and South Africa". Biological Control 45 (2010): 72-84.

5. Weller DM., et al. "Role of 2,4-diacetylphloroglucinol-producing fluorescent Pseudomonas spp. in the defense of plant roots". Plant Biology (Stuttg). 9.1 (2007): 4-20.

6. Lugtenberg B and Kamilova F. "Plant-growth-promoting rhizobacteria”. Annual Review of Microbiology 63 (2009): 541-556.

7. Deepa CK., et al. "Isolation and characterization of plant growth promoting bacteria from non-rhizospheric soil and their effect on cowpea (Vigna unguiculata (L.) Walp.) seedling growth". World Journal of Microbiology and Biotechnology 26 (2010): 1233-1240.

8. Suresh A., et al. "Plant growth promoting activities of fluorescent pseudomonads associated with some crop plants". African Journal of Microbiology Research 4 (2010): 1491-1494.

9. Noori MSS and Saud HM. "Potential plant growth-promoting activity of Pseudomonas sp. isolated from Paddy soil in Malaysia as biocontrol agent". Journal of Plant Pathology and Microbiology 3 (2012): 120.

10. Gordon SA and Weber RP. "Colorimetric estimation of indole acetic acid". Plant Physiology 26 (1951): 192-195.

11. Schwyn B and Neilands JB. "Universal chemical assay for the detection and determination of siderophore". Annals of Biochemistry 160 (1987): 47-56.

12. Bakker AW and Schipper B. "Microbial cyanide production in the rhizosphere in relation to potato yield reduction and Pseudomonas sp. mediated plant growth stimulation". Soil Biology and Biochemistry 19 (1987): 451-457. 
13. Mehta S and Nautiyal CS. "An efficient method for qualitative screening of phosphate solubilizing bacteria". Current Microbiology 43 (2001): 51-56.

14. Michel BE and Kaufmann MR. "The osmotic potential of polyethylene glycol 6000". Plant Physiology 51 (1973): 914-916.

15. Sandhya V and Ali SkZ. "The production of exopolysaccharide by Pseudomonas putida GAP-P45 under various abiotic stress conditions and its role in soil aggregation". Microbiology 84 (2015): 512.

16. Fernando C. "Screening tests for antibiotics". Mycologia 39 (1947): 128-30.

17. Powthong P., et al. "Screening of active antimicrobial and biological enzymes of microbial isolated from soil in Thailand". Asian Journal of Pharmaceutical and Clinical Research 10.4 (2017): 73-78.

18. Chen WP and Kuo TT. "A simple and rapid method for the preparation of Gram-negative bacteria genomic DNA". Nucleic Acids Research 21 (1993): 2260.

19. Ali SkZ., et al. "Isolation and characterization of drought-tolerant ACC deaminase and exopolysaccharide-producing fluorescent Pseudomonas sp". Annals of Microbiology 64 (2014): 493.

20. Zaidi A., et al. "Role of phosphate solubilizing bacteria in legume improvement”. In: Zaidi A., Khan M.S. and Musarrat J. Eds., Microbes for Legume Improvement. Springer (2017): 175-197.

21. Ahmad S., et al. "Effect of rhizobacteria inoculation and humic acid application on canola (Brassica napus L.) crop". Pakistan Journal of Botany 48.5 (2016): 2109-2120.

22. Ndeddy Aka RJ and Babalola 00. "Effect of bacterial inoculation of strains of Pseudomonas aeruginosa, Alcaligenes feacalis and Bacillus subtilis on germination, growth and heavy metal (Cd, Cr, and $\mathrm{Ni}$ ) uptake of Brassica juncea". International Journal of Phytoremediation 18.2 (2016): 200-209.

23. Rana A., et al. "Identification of multi-trait PGPR isolates and evaluating their potential as inoculants for wheat". Annals of Microbiology 61.4 (2011): 893-900.

24. Zhang J., et al. "Isolation and characterization of plant growthpromoting rhizobacteria from wheat roots by wheat germ agglutinin labeled with fluorescein isothiocyanate". The Journal of Microbiology 50.2 (2012): 191-198.
25. Kumar M., et al. "Synergistic effect of Pseudomonas putida and Bacillus amyloliquefaciens ameliorates drought stress in chickpea (Cicer arietinum L.)". Plant Signal Behavior 11 (2016): e1071004.

26. Rijavec T and Lapanje A. "Hydrogen Cyanide in the Rhizosphere: Not Suppressing Plant Pathogens, but Rather Regulating Availability of Phosphate". Frontiers in Microbiology 7 (2016): 1785.

27. Ahmad F., et al. "Screening of free-living rhizospheric bacteria for their multiple plant growth promoting activities". Microbiology Research 163.2 (2008): 173-181.

28. Mercado-Blanco J and Bakker PA. "Interactions between plants and beneficial Pseudomonas spp. exploiting bacterial traits for crop protection". Antonie Van Leeuwenhoek 92.4 (2007): 367389.

29. Siciliano SD., et al. "Differences in the microbial communities associated with the roots of different cultivars of canola and wheat". Canadian Journal of Microbiology 44 (1998): 844-851.

30. Roberson EB and Firestone MK. "Relationship between Desiccation and Exopolysaccharide Production in a Soil Pseudomonas sp". Applied and Environmental Microbiology 58.4 (1992): 1284-1291.

31. Sandhya V., et al. "Alleviation of drought stress effects in sunflower seedlings by the exopolysaccharides producing Pseudomonas putida strain GAP-P45". Biology and Fertility of Soils 46 (2009): 17-26.

32. Vurukonda SSKP., et al. "Multifunctional Pseudomonas putida strain FBKV2 from arid rhizosphere soil and its growth promotional effects on maize under drought stress". Rhizosphere 1 (2016): 4-13.

33. Konnova SA., et al. "Study of protective role of the polysaccharide-containing components of capsules of Azospirillum brasilense". Mikrobiologiia 70.4 (2001): 503-508.

34. Ali SkZ., et al. "Effect of inoculation with a thermotolerant plant growth promoting Pseudomonas putida strain AKMP7 on growth of wheat (Triticum spp.) under heat stress". Journal of Plant Interactions 6.4 (2011): 239-246.

35. Vyas $\mathrm{P}$ and Kaur R. "Plant growth promoting and antagonistic endophytic bacteria from the medicinal plant Tinospora cordifolia stem". International Journal of Research in Pharmaceutical Science 8 (2017): 189-193. 
36. Kuan KB., et al. "Plant growth-promoting rhizobacteria inoculation to enhance vegetative growth, nitrogen fixation and nitrogen remobilization of maize under greenhouse conditions". PLOS One 11.3 (2016): e0152478.

37. Araujo FF. "Seed inoculation with Bacillus subtilis, formulated with oyster meal and growth of corn, soybean and cotton". Ciência e Agrotecnologia 32.2 (2008): 456-462.

38. Wang LT., et al. "Comparison of gyrB gene sequences, $16 \mathrm{~S}$ rRNA gene sequences and DNA-DNA hybridization in the Bacillus subtilis group. International Journal of Systematic and Evolutionary Microbiology 57 (2007): 1846-1850.

39. Praveen Kumar G., et al. "In vitro screening for abiotic stress tolerance in potent biocontrol and plant growth promoting strains of Pseudomonas and Bacillus spp". International Journal of Bacteriology 6 (2014): 2014.

\section{Assets from publication with us}

- Prompt Acknowledgement after receiving the article

- Thorough Double blinded peer review

- Rapid Publication

- Issue of Publication Certificate

- High visibility of your Published work

Website: www.actascientific.com/

Submit Article: www.actascientific.com/submission.php

Email us: editor@actascientific.com

Contact us: +919182824667 